7. Azevedo MC, Ramuno NM, Fachin LR, Tassa M, Rosa PS, Belone AF, et al. qPCR detection of Mycobacterium leprae in biopsies and slit skin smear of different leprosy clinical forms. Braz J Infect Dis. 2017;21:71-8. https:/ / doi.org/ 10.1016/j.bjid.2016.09.017

8. Lugton I. Mucosa-associated lymphoid tissues as sites for uptake, carriage and excretion of tubercle bacilli and other pathogenic mycobacteria. Immunol Cell Biol. 1999;77:364-72. https:/ / doi.org/10.1046/j.1440-1711.1999.00836.x

Address for correspondence: Marilda A.M. Morgado de Abreu, rua São Paulo, 1949, centro, CEP 17900-000, Dracena, SP, Brazil; email: marilda@morgadoeabreu.com.br

\section{Fatal Chlamydia avium Infection in Captive Picazuro Pigeons, the Netherlands}

\author{
Marja Kik, Marloes Heijne, Jooske IJzer, Guy \\ Grinwis, Yvonne Pannekoek, Andrea Gröne
}

Author affiliations: Utrecht University, Utrecht, the Netherlands (M. Kik, J. IJzer, G. Grinwis, A. Gröne); Wageningen Bioveterinary Research, Lelystad, the Netherlands (M. Heijne); University of Amsterdam, Amsterdam, the Netherlands (Y. Pannekoek)

DOI: https://doi.org/10.3201/eid2610.191412

In 2016, an outbreak of Chlamydia avium infection occurred among Picazuro pigeons (Patagioenas picazuro) living in an aviary in the Netherlands. Molecular typing revealed a unique strain of $C$. avium. Our findings show that $C$. avium infection, which usually causes subclinical infection, can cause fatal disease in pigeons.

Ut ntil approximately 2014, Chlamydia psittaci was the only Chlamydia species detected in birds. Researchers have catalogued $\approx 465$ bird species affected by this pathogen, which mainly causes subclinical infections but sometimes results in acute disease and death (1). In humans, C. psittaci is highly infectious and can cause severe pneumonia. Chlamydia bacteria, which are present in (dried) excreta or feather dust, are transmitted through direct contact or inhalation. In 2014, researchers proposed 2 new members of Chlamydiaceae: C. avium and C. gallinacea (2). C. avium affects pigeons and psittacine birds, whereas
C. gallinacea affects poultry. Most C. avium and C. gallinacea infections in birds are subclinical, and the zoonotic potential of these species is unknown (3).

In 2016, an outbreak of C. avium infection occurred among 11 Picazuro pigeons (Patagioenas picazuro) housed in an aviary with other bird species in the Netherlands. The birds lost weight, had ruffled feathers, and were anorexic. Despite treatment with fluids, force-feeding, and in 1 bird, doxycycline treatment $(50 \mathrm{mg} / \mathrm{kg} 1 \times / \mathrm{d})$, all 11 animals died or were euthanized. Necropsy revealed that 9 of these birds were in poor physical condition, lacking fat and pectoral muscle mass. The livers and spleens were enlarged; the livers extended an average of $0.5 \mathrm{~cm}$ beyond the rear edge of the sternum, whereas the mean diameter of the spleens was $1.0 \mathrm{~cm}$, approximately twice as large as the normal size. We suspected Chlamydia infection because of intracellular inclusions in Stamp (modified Ziehl Neelsen)-stained cytology of liver and spleen. We found multifocal heterophilic and lymphoplasmacytic infiltrates with necrosis in the liver and lymphoid depletion with necrosis and heterophilic infiltrates in the spleen. We stained slides with polyclonal antibodies against Chlamydia (bioMérieux, https://www.biomerieux.com) after a standard Avidin Biotin Complex protocol (4); liver and kidney tissues from 7 birds tested positive for Chlamydia. We did not observe any histologic changes consistent with viral inclusions or bacterial infection.

Because psittacosis in birds is a notifiable disease in the Netherlands, we informed public health authorities of our results. We forwarded frozen tissue samples to the Wageningen Bioveterinary Research institute to confirm C. psittaci infection. We also collected and forwarded 2 Picazuro pigeon carcasses and 3 pooled fecal samples from contact birds (i.e., Roseate spoonbill [Platalea ajaja], Puna ibis [Plegadis ridgwayi], and Scarlet ibis [Eudocimus ruber]), from the aviary. Two liver samples, 2 conjunctival and cloacal swabs, and 3 pooled fecal samples initially tested negative for C. psittaci, C. abortus, C. felis, and C. caviae in a PCR selective for the ompA gene. Because the liver and kidney samples of 7 pigeons tested positive for antibodies against Chlamydia, we submitted samples from all 11 pigeons and the 3 pooled fecal samples for further testing with real-time PCR selective for the 235 gene of Chlamydiaceae (5) and a duplex real-time PCR selective for C. gallinacea and C. avium $(3,6)$. All 11 pigeons tested positive for $C$. avium in $\geq 1$ samples of conjunctiva, cloaca, liver or intestines. The pooled fecal samples of contact birds tested negative in a PCR for Chlamydiaceae (Appendix, https://wwwnc. cdc.gov/EID/article/26/10/20-0086-App1.pdf). 
We used Buffalo green monkey cells to isolate Chlamydia from the spleen of 1 of the pigeons that tested positive. Multilocus sequence typing using the concatenated sequences of 7 housekeeping genes revealed that this isolate is a unique sequence type, 254, that is closely related to the other $3 \mathrm{C}$. avium strains previously described (2) (Figure).

The clinical signs, histopathologic results, and positive intralesional immunohistochemistry findings
(Appendix) showed that the birds had generalized disease consistent with a Chlamydia infection. Realtime PCR revealed an infection with $C$. avium. Further analysis with multilocus sequence typing showed the isolated strain is unique, but most closely related to other reported $C$. avium strains. C. avium has been detected mainly in urban or feral pigeons without clinical signs and in co-infections of feral pigeons with C. psittaci (2).

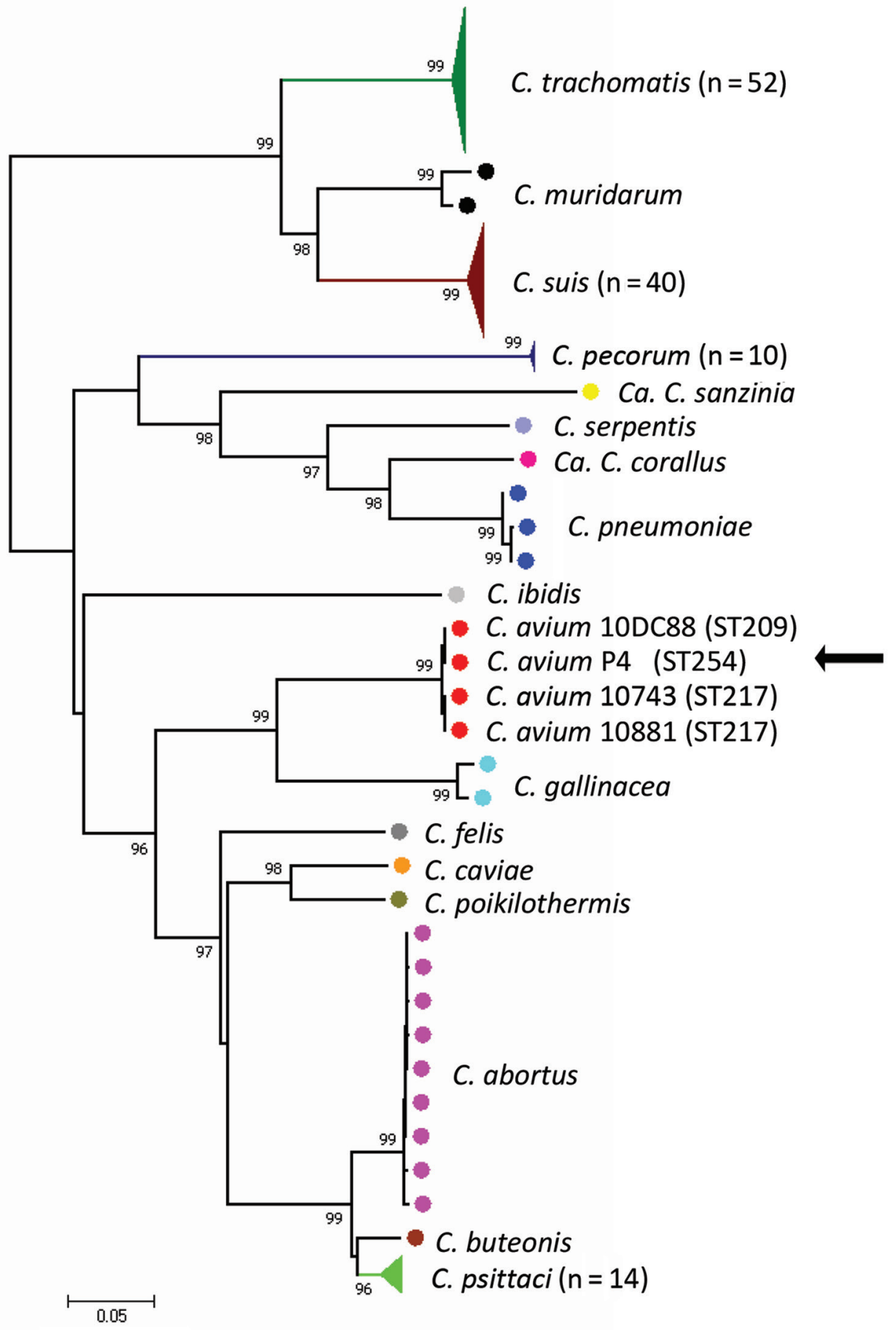

Figure. Phylogenetic analyses of concatenated sequences of 7 housekeeping gene fragments of Chlamydiaceae, the Netherlands, 2016. Numbers indicate bootstrap values $>90 \%$. Filled circles represent isolates, colored by species. Filled colored triangles represent $>9$ isolates of the same species; total number of isolates used for the analyses is indicated. The sequence types of the $C$. avium isolates are labeled. $C$. avium isolate $\mathrm{P} 4$ is indicated by the arrow. Scale bar indicates sequence divergence. ST, sequence type. 
Our results show that $C$. avium strains might also cause severe, potentially fatal infections in birds. Data on C. avium are limited, but several factors might explain the severity of the clinical signs. Unlike previously reported cases, these pigeons were held in captivity. Furthermore, we cannot exclude possible differences in virulence between sequence types of C. avium. No human cases were reported during this outbreak, so the zoonotic potential of $C$. avium remains unknown.

\section{Acknowledgments}

We thank Rachel Thomas for proofreading. We also thank Frank Harders and Annemieke Dinkla for their technical assistance in DNA isolation and sequencing.

This work was partly funded by the Dutch Ministry of Agriculture, Nature and Food Quality (grant no.

WOT-01-002-005.02).

\section{About the Author}

Dr. Kik is a veterinary pathologist at Utrecht University. Her research interests include the pathology of exotic animals and wildlife.

\section{References}

1. Kaleta EF, Taday EM. Avian host range of Chlamydophila spp. based on isolation, antigen detection and serology. Avian Pathol. 2003;32:435-62. https:/ / doi.org/10.1080/0307945031 0001593613

2. Sachse K, Laroucau K, Riege K, Wehner S, Dilcher M, Creasy $\mathrm{HH}$, et al. Evidence for the existence of two new members of the family Chlamydiaceae and proposal of Chlamydia avium sp. nov. and Chlamydia gallinacea sp. nov. Syst Appl Microbiol. 2014;37:79-88. https://doi.org/ 10.1016/j.syapm.2013.12.004

3. Sachse K, Laroucau K. Two more species of Chlamydiadoes it make a difference? Pathog Dis. 2015;73:1-3. https://doi.org/10.1093/femspd/ftu008

4. Key M. Immunohistochemical staining methods. In: Kumar GL, Rudbeck L, editors. Immunohistochemical staining methods. 5th ed. Carpinteria (CA): Dako Corporation; 2009. p. 57-60.

5. Zocevic A, Vorimore F, Vicari N, Gasparini J, Jacquin L, Sachse K, et al. A real-time PCR assay for the detection of atypical strains of Chlamydiaceae from pigeons. PLoS One. 2013;8:e58741. https:// doi.org/10.1371/journal. pone. 0058741

6. Pannekoek Y, Morelli G, Kusecek B, Morré SA, Ossewaarde JM, Langerak AA, et al. Multi locus sequence typing of Chlamydiales: clonal groupings within the obligate intracellular bacteria Chlamydia trachomatis. BMC Microbiol. 2008;8:42. https://doi.org/10.1186/1471-2180-8-42

Address for correspondence: Marja Kik, Faculty of Veterinary Medicine, Pathobiology, Utrecht University, Yalelaan 1, 3584 CL Utrecht, the Netherlands; email: info@kikdierenarts.nl

\section{Streptococcus equi Subspecies zooepidemicus and Sudden Deaths in Swine, Canada}

\author{
Matheus de O. Costa, Brad Lage
}

Author affiliations: University of Minnesota, St. Paul, Minnesota, USA (M.O. Costa); University of Saskatchewan, Saskatoon, Saskatchewan, Canada (M.O. Costa); Utrecht University, Utrecht, the Netherlands (M.O. Costa); Maple Leaf Agri-Farms, Landmark, Manitoba, Canada (B. Lage)

DOI: https://doi.org/10.3201/eid2610.191485

Historically described as a commensal of the swine upper respiratory tract, Streptococcus equi subspecies zooepidemicus was previously reported as an important swine pathogen only in Asia. Here we report the isolation and whole genome characterization of $S$. equi subsp. zooepidemicus associated with a sudden death outbreak in pigs in Canada.

Streptococcus equi subspecies zooepidemicus is con$\checkmark$ sidered a commensal and opportunistic pathogen of several warm-blooded hosts, including humans, horses, canines, and swine. It is a gram-positive, $\beta$-hemolytic coccus belonging to the Lancefield group $C$ and can cause severe disease characterized by pneumonia, septicemia, and meningitis $(1,2)$. S. equi subsp. zooepidemicus has been suggested as a normal inhabitant of the palatine tonsils of pigs, being detected by both culture and high-throughput sequencing in samples collected from healthy animals (3). However, strains virulent to pigs have also been reported, particularly associated with high-mortality outbreaks of sudden death and respiratory disease in China (4). No vaccines are available for this pathogen, and control and prevention methods are rarely applied because of its normally harmless commensal nature in swine. Here, we report an outbreak of sudden death associated with S. equi subsp. zooepidemicus in pigs housed in intensive commercial rearing facilities in Canada.

In April 2019, an outbreak of sudden deaths and abortions occurred in 4 loose-housed, commercial sow farms $(\approx 9,000$ sows $)$ in a large vertically integrated swine system in Manitoba, Canada. This outbreak increased the cumulative death in the 3 affected sow herds by $>1,000$ animals over a 12 -week period. The abortion rate during this time was $\approx 11 \times$ normal.

The sows were often described as apparently healthy during morning checks. However, over the course of hours, infected sows would become 